\title{
The Linkage between Governance and Growth
}

\author{
Adirek Vajrapatkul \\ School of Economic, Sukhothai Thammathirat Open University, Thailand
}

\begin{abstract}
Quality of government is a precondition for economic growth and development as it can lead to the improvement of government's work efficiency and effectiveness as well as trust from its citizen. To improve its quality, the government needs to complete some specific functions which are combined to form the so-called "good governance". This governance is defined by various functions of government and its positive influence on economic growth has been proved by previous works of many scholars. Although the overall picture of the linkage between governance and economic growth has been derived, it is still valuable to elaborate more on the linkage between each composition of governance and the growth of the economy. Thus, in this work, we represent such linkage by proving the linkage between some functions defined by governance, namely corruption control, regulatory quality improvement, and accountability creation, and economic growth. To meet our objective, we utilized the data of 10 ASEAN countries from the World Bank database which covers the period between 1996 and 2018 and the panel regression technique to verify such linkage. The results produced from the cointegration test showed that corruption control and accountability were positively linked to economic growth, while the regulation quality linked negatively to economic growth. Therefore the government should focus on reducing corruption, improving accountability and optimally regulating its economy to encourage economic growth.
\end{abstract}

Keywords: Corruption control, Regulatory quality, Accountability, Panel data, ASEAN countries.

\section{Introduction}

In the economic framework, the basic engines that drive the growth of the economy include both domestic and foreign governments, households, and firms. The households can drive economic growth by spending on products and services and supporting their resources using as inputs for productions. Likewise, firms can contribute the economic growth by creating and producing products and services. Also, the government can encourage economic growth by controlling the economic condition via the utilization of monetary and fiscal policy.

If we take a moment to consider the above statements, we will realize that they highlight the functions of each engine in driving growth within our economy. But how about the quantity and quality. An increase in quantity is easy to observe and directly expect the effect on economic growth. There were theories and many works that explain the relationship between those two which one can learn in (Becker et al., 1999) (Carree \& Thurik, 2010) (Memili et al., 2015) (Peterson, 2017). However the quality is more difficult in term of both observation and its effects on national income growth identification.

To be specific to the purpose of this study, the question is how we can measure the quality of government and how it affects the growth of our economy? In term of government quality, 
it widely agrees that good governance is an appropriate choice for measuring such quality (Rothstein \& Teorell, 2008) (Fukuyama, 2013) (Nguyen et al., 2018). Also, there were theories and several previous works that explained the effects of that governance on the economic growth but in different contexts (Rivera- Batiz, 2002) (Feng, 2003) (S. D. Sharma, 2007) (Yerrabati \& Hawkes, 2015) (Alshammari et al., 2019).

Defended by World Bank, there are six key components of good governance, i.e., Corruption control, Government effectiveness, The rule of law, Violence and accountability, Regulation quality, and Political stability and absence of violence (World Bank, 2021b)

Good governance implies a capable government in improving the capital market and investment climate, the stability of the bureaucratic system, the economic and political power structure, quality of public services (Liu et al., 2018), the local and national involvement, the quality of formulated policies, and the ability to exercise power and make good decisions involving all aspects of a country to achieve the goals (Bercu et al., 2019).

Governance will stimulate investment from both domestic and foreign by reducing uncertainty and creating an attractive investment environment. It can affect economic growth by improving, e.g., resource utilization, budget management, investment regulation, financial market, and firm performance (Bayar, 2016). However, the economic growth gained from good governance may depend on the levels of development of nations (AlBassam, 2013).

To learn the effects of good governance or the quality of government on economic growth, some previous work employed the governance composite index as an explained variable, whereas some employed only particular elements embedded in such composite index. However, we follow the second choice as we interest in learning the specific effect of some element consisted in governance definition. To meet our objective, we organize our work as follow. In the next Section, it will present the knowledge gained from some pieces of related literature. Section 3 will highlight the methodology. The results and discussion will be conducted in Section 4. In Section 5, the policies for fostering economic growth will be proposed.

\section{Literature review}

In the following, we will highlight the associations between economic growth and our three explained variables, i.e., corruption control, regulation quality, and accountability.

\subsection{Corruption control and economic growth}

Corruption, an issue concerned in the governance composite index, can be used to indicate the level of institution quality, government quality for this research particular purpose, and can be a cause of the reduction in productivity and social benefits of public expenditure, e.g., education and health expenditure benefits (Kim et al., 2017). This limitation of benefits that should be gained from public expenditures means that the growth potentials offered by public expenditure are limited too.

Defined by the World Bank, Corruption is the abuse of government officials for private gain. It is every illegal transaction between the public and private actors for private benefits (Thach et al., 2017). Primarily, corruption has focused on bribes to public officials made by entrepreneurs to avoid taxation and regulation and to win public contracts. Although the prevalence of corrupt behaviours can be influenced by various factors, the national culture is a dominant one (Ivanyna et al., 2016). 
Two interesting hypotheses state the cost and benefit of corruptions. The first hypothesis is the 'sand the wheels' hypothesis, it views corruption as one of the serious obstacles to the growth, development and welfare of the nation because it encourages rent-seeking behaviour and social cost. The second hypothesis is the 'grease the wheels' hypothesis which argues for the benefit of corruption that helps in improving the economic performance (C. Sharma \& Mitra, 2019), allowing firms circumvent government regulation to meet the firm growth objective, and acting as an important buffer for solving many economic problems (Hoinaru et al., 2020).

However, many scholars intend to believe in the sand the wheels' hypothesis, because they believe that corruption can bound the economic growth by hindering both internal and external productive investment, discouraging entrepreneur development, reducing the quality of infrastructures, and diverting the talent into rent-seeking which distorts the composition of public expenditure (Yusuf et al., 2014). Also, it can prevent the use of productive resources by enacting cumbersome procedures, delay permits and licenses, divert resources to those who succumb to corrupt practices, and distort market information by increasing the costs of doing business (Borja, 2017).

In general, corruption can affect resource allocation in two ways. First, it can change private investors' assessments of investment merits. Because corruption can induce changes in the relative prices of goods, services, and factors of production. Second, it can cause resource misallocation in public and private investments induced by the decision of a corrupt government agency. Corruption significantly slows down foreign direct investment and the stream of foreign aid (Amin et al., 2013).

Corruption can be viewed as a burden on a nation's wealth by discouraging new investment, creating uncertainties on investment, diminishing investment incentive, reducing the accumulation of human capital, increasing the country risk perceive level which can cause movements of capital in the negative directions (Cieślik \& Goczek, 2018). These can decrease consumer and investor confidence and trust of the society which produce a negative effect on economic growth (Samarasinghe, 2018).

The previous empirical results. they showed that a decrease in corruption raises the economic growth rate in an inverted U-shaped (Ahmad et al., 2012); it has a negative impact on per capita income (Amin et al., 2013); There had a long-run relationship between corruption and economic growth, i.e., the reduction in corruption will improve GDP growth (Yusuf et al., 2014); the less corrupt countries enjoy higher rates of return from FDI and remittances (Borja, 2017); the effect of public debt on economic growth is a function of corruption, thus to alleviate the negative effect of public debt on economic growth, governments should strive to eliminate corruption (Kim et al., 2017); the lack of corruption is found to have a positive and statistically significant effect on the growth rate of real per capita GDP and increased the investment ratio (Cieślik \& Goczek, 2018); control of corruption is a critical factor for economic growth (Samarasinghe, 2018).

However, corruption impacted economic growth differently depended on the level of development, i.e., at the low quantile level, corruption impacts positively on economic growth, but at the high level, it impact negatively on the growth (Thach et al., 2017); the lower-middleincome countries. anti-corruption measures would contribute to economic growth (C. Sharma \& Mitra, 2019); corruption is poverty-driven diseases, particularly in low-income countries and it negatively correlates with economic and sustainable development (Hoinaru et al., 2020). To verify the negative effect of corruption on economic growth in our research context, we set the following hypothesis:

Hypothesis 1: corruption control has a significant positive effect on economic growth 


\subsection{Regulation quality and economic growth}

An alternative practices for investigating the economic growth inducing factors, which often based on the socio-economic factors, e.g., savings, investment, human capital, and technology, is the investigation of the institution effects, primarily political and economic institutions which relate to, e.g., legal, regulations, and cultures, on economic growth (DOĞANAY \& DEĞER, 2021). Aside from the economic main streams, the school of institutional economics expressed that the formal legal rules are a facilitator of economic growth and development, because such rules support the protection of property rights, discourage opportunism and uncertainty, enhance investments and innovations and so lead to increase of per capita income (Issever Grochová, 2015). Also, in the literature area, it was argued that in the proper legal environment, where the contracts are enforced and property rights are protected, the check and balance will work to support investment and economic growth (Güvercin \& Adem, 2019).

In a particular area, it has been recognized that regulatory quality is an important factor for human capital development which expected to have a positive spill-over effect on economic growth (Mongale \& Masipa, 2019). At an industry level, a best fit legal and regulation can, e.g., cause financial development which increases the efficiency of capital accumulation and savings (Güvercin \& Adem, 2019); yield greater investment in energy infrastructure and capacity (Cebula \& Mixon Jr, 2014), create an environment that encourages the sustainable investment in energy R\&D and infrastructure (Cebula \& Mixon Jr, 2014); rise the growth of wind and solar-PV output (Ibarra-Yunez \& Pérez-Henríquez, 2017). All of these, therefore, support economic growth.

In the empirical area, it found that regulatory quality is associated with the expansion of international business and higher economic growth (Jalilian et al., 2006); quality of regulation is found to raise growth significantly in the developing countries (C. Sharma \& Mitra, 2019); regulatory quality, total fixed capital formation, total consolidated expenditure on health do have a positive relationship with growth (Mongale \& Masipa, 2019); regulatory quality increase banking and stock market development and so increases income per capita (Güvercin \& Adem, 2019); regulatory quality positively affects economic growth (DOĞANAY \& DEĞER, 2021). However, a piece of evidence that shows uncorrelated between regulatory quality and economic growth could be found in (Jalilian et al., 2006). Regarding an issue of regulation quality and economic growth, we write the following hypothesis:

Hypothesis 2: regulatory quality has a significant positive effect on economic growth

\subsection{Accountability and economic growth}

Like an individual, the government has private interests. However, unlike an individual, the government can impose some costs on citizens by what we called "rent extraction behaviours". However, these costs and behaviours of the government can be controlled by the wellfunctioning accountability mechanisms (Benhabib \& Przeworski, 2010). Here accountability is a major concern. The term "accountability" is a dimension of governance that directly related to participation, transparency, and democracy which are necessary for contract enforcement, safeguarding of law and order, market expansion, and economic growth (Samarasinghe, 2018). Accountability will help to elaborate on economic policies and the rule of law and premising for generating economic performance (Boţa-Avram et al., 2018).

It was argued that it does not necessary for all well-designed policies will work to meet the objective. Because whether the policy objective will be met or not is depended on the 
accountability of the government, e.g., the aim to control inflation will achieve or not depend on how much the government accountable for its actions (Morozumi \& Veiga, 2016).

To improve government accountability, the government may need to create a decentralized decision-making process, participation, transparency, and mechanisms that aimed to reduce corruption. One strategy that should effectively support this accountability improvement is to educate citizen and let them know their rights and responsibilities in improving their life and social welfare (Fayissa \& Nsiah, 2013).

At the organization level, accountability can be achieved by building the capacities of accountability systems by 1) controlling hierarchical structures, 2) monitoring bureaucratic behaviour of political leaders and gaining feedback from citizens, and 3) linking citizen-users more directly to service providers (Levy, 2007). Whereas at the project implementation level, accountability can be achieved by project appraisal, selection, implementation, and evaluation which allow an independent peer review, the information discloses to the public, the comprehensive expenditure controls, and the auditors (Morozumi \& Veiga, 2016).

The result from empirical investigations showed that the correlation between GDP and voice and accountability for high development countries was found to be significant but weak and negative (AlBassam, 2013); accountable government play a critical role in the effectiveness of capital spending which promote economic growth (Morozumi \& Veiga, 2016). Nevertheless, the negative impact of voice and accountability on economic growth can be found in (Salawu et al., 2018). To test the impact of accountability on economic growth, we set the following hypothesis:

Hypothesis 3: Accountability has a significant positive effect on economic growth

\section{Methodology}

To test our hypotheses, we employ the data from the World Bank database for the period of 1994 to 2016. Therefore with 10 ASEAN countries, we have 240 observations under a balanced data dataset (Asteriou \& Hall, 2007). For the variables, we use GDP, CC, RQ, and VA with the following definitions. Control of Corruption (CC) captures perceptions of the extent to which public power is exercised for private gain, including both petty and grand forms of corruption, as well as "capture" of the state by elites and private interests. This table lists the individual variables from each data source used to construct this measure in the Worldwide Governance Indicators. Regulatory Quality (RQ) captures perceptions of the ability of the government to formulate and implement sound policies and regulations that permit and promote private sector development. Voice and Accountability (VA) capture perceptions of the extent to which a country's citizens can participate in selecting their government, as well as freedom of expression, freedom of association, and free media (World Bank, 2021a).

Before analyzing the obtained data, we tried to clean the data and checked the basic assumptions to avoid inaccurate results. Nevertheless, the linear regression assumptions testing may not necessarily to be conducted in panel data analysis because one of the benefits of panel data analysis is that it can handle better with the issue coming from violations of regression assumptions (Stock \& Watson, 2015).

As panel data combine the time-series with cross-sectional data, the panel data analysis become the most effective analytical method to handle this data type. In this research context, we can express such a combination between $n$ different observed entities and $T$ different periods (Stock \& Watson, 2015) by the following equation:

$$
Y_{i t}=f\left(X_{i t}\right) \text {, }
$$




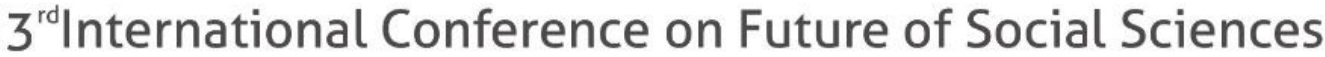

\section{5 - 7 March 2021}

where $i=1,2, \ldots, n$ represents the country variety and $t=1,2, \ldots, T$ is the time interval.

Here, we can write a simple linear panel data model with one explanatory variable as follows:

$$
Y_{i t}=\alpha+\beta X_{i t}+u_{i t}
$$

Regarding the country-specific factors, we thus need to consider the properties of the fixed effects and the random-effects model. For the fixed effects model, which is also known as the least-squares dummy variables (LSDV) model, where each entity is constant over time but differ across entities, i.e., allows for different constants $\alpha_{i}$ for each group (Stock $\&$ Watson, 2015). So we can show the fixed effects model as:

$$
Y_{i t}=\alpha_{i}+\beta X_{i t}+u_{i t}
$$

For the random-effects model, this model treats the constants $\alpha_{i}$ for each section as random parameters (Greene, 2012). Therefore, this model can be represented by:

$$
Y_{i t}=\alpha_{i}+\beta X_{i t}+u_{i t}
$$

where $\alpha_{i}=\alpha+v_{i}$ and $v_{i}$ is a zero-mean standard random variable.

The fixed-effects model is preferred to be used for balanced panel data, whereas if the panel data is unbalanced, the random-effects model is more appropriate (Vijayakumar et al., 2010). To choose between fixed effects and random effects model, a Hausman test is conducted (Hausman, 1978) to test the following hypothesis:

$H_{0}=$ Random-effects model is appropriate

$H_{i}=$ Fixed effects model is appropriate

By extending the simple panel data model to cover all variables in this work, we write the following model:

$$
D G D P_{i t}=\alpha+\beta_{1} C C_{i t}+\beta_{2} R Q_{i t}+\beta_{3} V A_{i t}+\varepsilon_{i t},
$$

\section{Result and Discussion}

Before processing hypotheses testing, we present the movement of all variables of 10 ASEAN countries in Fig. 1. According to Fig. 1, we can roughly observe the direction of the relationship between all of these variables, especially the positive relationship between GDP, CC, RQ, and VA. However, testing the data without making them stationary, may lead us to the wrong conclusions.

Figure 1: the movement of Gross domestic product, Corruption Control, Regulatory Quality, Voice and Accountability of 10 ASEAN countries. 


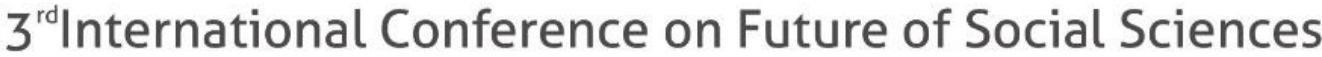

\section{5 - 7 March 2021}

VNM

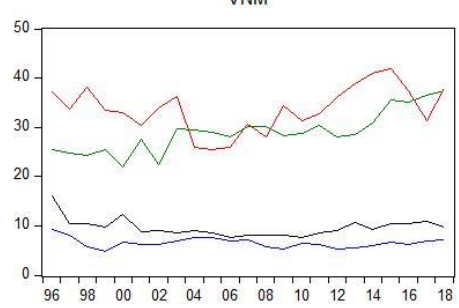

(a) Vietnam

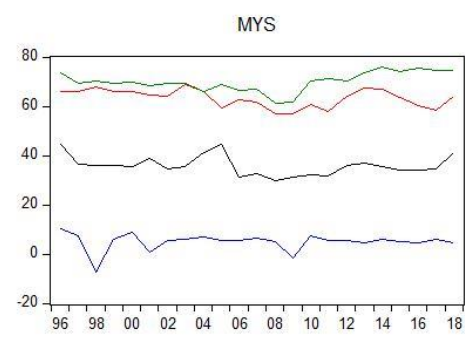

(d) Malaysia

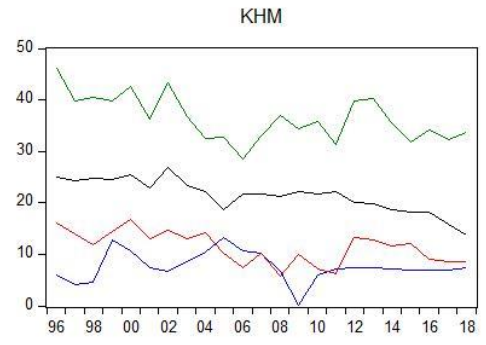

(g) Cambodia

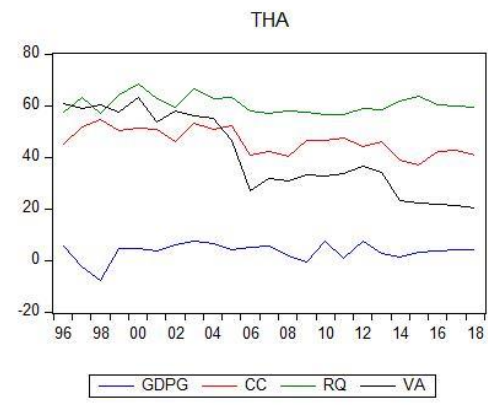

(j) Thailand

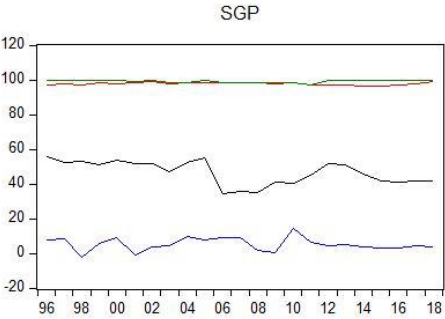

(b) Singapore

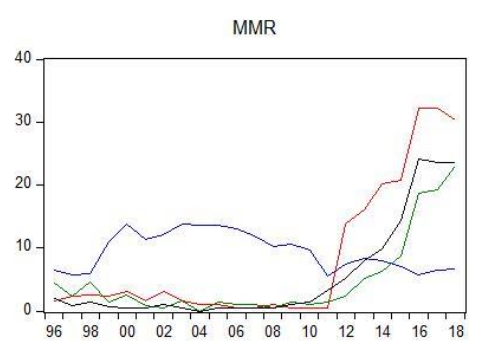

(e) Myanmar

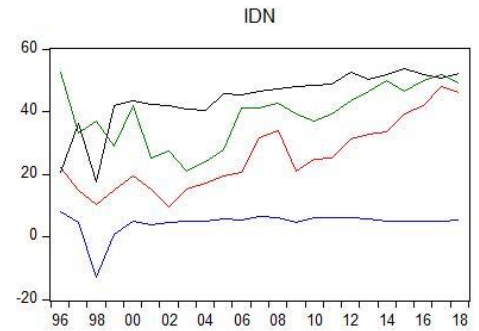

(h) Indonesia

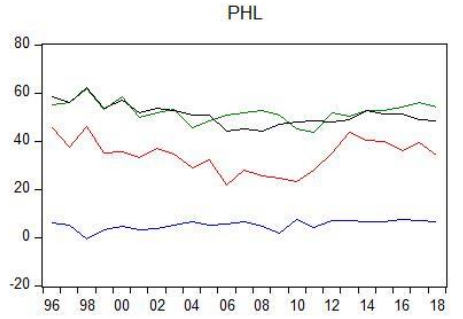

(c) Philippines

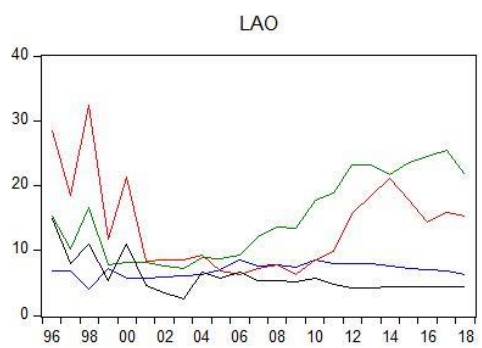

(f) Lao PDR

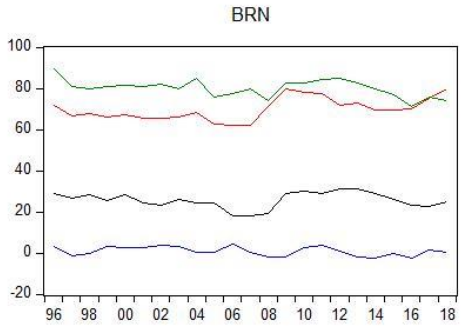

(i) Brunei Darussalam

Source: Author' presentation

To satisfy the stationary condition of the data, we manipulate all variables by first-order differencing and conduct the unit root test. Based on the three test statistics for each variable showed in Tab. 1, we can state that the stationary condition is satisfied.

Table 1: Panel Unit root test for the first- order differencing variables

\begin{tabular}{llll}
\hline $\begin{array}{l}\text { Variables/Unit } \\
\text { root test }\end{array}$ & LLC & Fisher-ADF & Fisher-PP \\
\hline DGDP & $-4.40760^{* * *}$ & $69.6367^{* * * *}$ & $76.3938^{* * *}$ \\
DCC & $--3.78518^{* * *}$ & $70.7461^{* * *}$ & $81.8344^{* * *}$ \\
DRQ & $-4.36373^{* * *}$ & $67.5935^{* * *}$ & $87.5184^{* * *}$
\end{tabular}




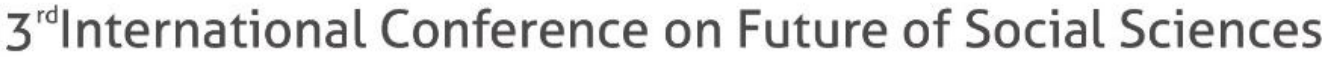

\section{5 - 7 March 2021}

BERLIN, GERMANY

\begin{tabular}{|c|c|c|c|}
\hline DVA & $-6.92676^{* * *}$ & $108.722^{* * * *}$ & $110.372^{* * *}$ \\
\hline
\end{tabular}

Next, we decide whether a fixed effect or random effect model is appropriated for testing our hypotheses. For this purpose, we carry out the Hausman specification test. Tab. 2 demonstrates the result and it shows that the p-value is 0.0248 which is less than 0.05 (5\% significance level). Consequently, this implies that the random-effects model is appropriated.

Table 2: Hausman specification test

\begin{tabular}{lccc}
\hline Test Summary & Chi-Sq. Statistic & Chi-Sq. d.f. & Prob. \\
\hline Cross-section random & 1.224702 & 3 & 0.7471 \\
\hline
\end{tabular}

Source: Author' calculation

Now the results of panel data analysis with random effects model are summarized in Tab. 3. According to Tab. 3, it demonstrates that DCC and DVA are significantly and positively affect DGDP, whereas, DVA is significantly and negatively affect DGDP. Also, based on the result of the unit root test of residual (Barros \& Pereira, 2008) represented in Tab. 4, it implies the stationary of the linear combination of the set of variables which indicate the long-run relationship between DCC, DRQ, DVA and DGDP.

Table 3: Random effects model, DGDP as dependent Variable

\begin{tabular}{lcc}
\hline Variables & Coefficients & Unit \\
\hline DCC & $808.00^{* *}$ & Million Dollar \\
DRQ & $-798.00^{*}$ & Million Dollar \\
DVA & $811.00^{*}$ & Million Dollar \\
R-squared & 0.256 & \\
Prob(F-statistic) & 0.000 & \\
Durbin-Watson stat & 0.94 \\
\hline \multicolumn{3}{c}{ **denotes significance at the 5\% level, * denotes significance at the 10\% level } \\
\multicolumn{2}{r}{ Source: Author' calculation }
\end{tabular}

Table 4: Residual Unit root test

\begin{tabular}{llll}
\hline \multicolumn{4}{c}{ Table 4. Residual Unit root test } \\
\hline Variables/Unit root test & LLC & Fisher-ADF & Fisher-PP \\
\hline Residual & $-7.54741^{* * *}$ & $91.6669^{* * *}$ & $92.6518^{* * *}$ \\
\hline So* denotes significance at the 1\% level & & \\
Source: Author' calculation & &
\end{tabular}

The key message from Tab. 3 and Tab. 4 is that corruption control and accountability positively affected national income measured by gross domestic product. Nevertheless, the regulation quality affected negatively the national income. That is an increase of each unit of corruption control will bring about an additional 808 Million Dollar. Similarly, every additional unit of accountability will lead to an increasing of 811 Million Dollar in national income, respectively. On contrary, an increase in regulation quality would lead to a reduction of 798 Million Dollar in national income. These results lead us to conclude that our hypothesized economy which composed of the 3 selected elements of governance, i.e., CC, RQ and VA, could produce a different impact on economic growth. The possible explanation is that, as highlighted in the literature review Section, when a country emphasis reducing corruption, it will increase citizen's trust, reduce social cost, and improve efficiency in utilizing its national resources which raise national income. However, the effect of regulation quality deviated from 
our expected direction. It would imply that the sound policies and regulations that expected to promote private sector development, may work in the opposite direction. That is it may become an obstacle for such development by creating unnecessary process and inertia in business activities and investment.

\section{Policy Recommendation}

From the results of the analysis, we propose the following recommendations to related government agents who are in charge of encouraging economic activities and growth by continuously 1) reducing corruption which may be succeeded through checking and power balancing system, 2) increase its accountability which can be achieved via inviting more participation and feedback from relevance agents, and 3) optimizing the burden of regulations which may be attained by adjusting the perceived obstacle regulations to become the practical one that matches with the business and economic activities which support economic growth and development.

\section{Conclusion}

This work was conducted to study the impacts of three variables, chose from the componence of good governance, on economic growth. These 3 variables, i.e., corruption control, regulation quality, and accountability, were chosen by concerning their possible potential impacts on economic growth. We test our hypotheses by using panel data obtained from the World Bank database. The data of 10 ASEAN countries were collected and manipulated by first-order differencing to make them fit with the precondition of stationary. We then processed to choose an appropriate model which lead us to the random effect model. Also, we test for the cointegration of the panel data. After the analysis, we discover that corruption control and accountability had a positive effect on and long term relationship with national income, while the quality of regulation showed a negative relationship with such national income. Hence, reducing corruption, increase accountability, and optimizing the regulation were the policy recommendations that we proposed.

This work tries to contribute to the research in the governance area by linking it to the economic boundary of developing ASEAN countries for identifying the appropriate concepts for policy formulations. The set of variables drawing from the componence of good governance inspire the governance economy in the sense that, it linked the influence of government quality on economic growth. In this manner, the public policy designers will have more choices, beyond the choices derived from fiscal and monetary policy instruments, for flourishing economy growth by trying to manage these variable.

Still, this work did not cover other possible growth-related governance componence. Therefore, this may be a challenge for researchers who interest in this scope of research.

\section{Acknowledgements}

This research is supported by the school of economics, Sukhothai Thammathirat Open University (STOU), Thailand. This work is also supported by the Department of Economics, The University of Central Thailand (UCT), Thailand. 


\section{Reference}

Ahmad, E., Ullah, M. A., \& Arfeen, M. I. (2012). Does corruption affect economic growth? Latin American Journal of Economics, 49(2), 277-305.

AlBassam, B. A. (2013). The relationship between governance and economic growth during times of crisis. European Journal of Sustainable Development, 2(2), 1-1.

Alshammari, N., Alshuwaiee, W., \& Aleissa, N. (2019). Does "good" governance promote economic growth according to countries' conditional income distribution. Journal of Reviews on Global Economics, 8, 1046-1061.

Amin, M., Ahmed, A., \& Zaman, K. (2013). The relationship between corruption and economic growth in pakistan-Looking beyound the incumbent. Oeconomics of Knowledge, 5(3), 21.

Asteriou, D., \& Hall, S. G. (2007). Applied Econometrics: A modern approach, revised edition. Hampshire: Palgrave Macmillan, 46(2), 117-155.

Barros, A. A. de, \& Pereira, C. M. M. de A. (2008). Empreendedorismo e crescimento econômico: Uma análise empírica. Revista de Administração Contemporânea, 12(4), 975-993. https://doi.org/10.1590/S1415-65552008000400005

Bayar, Y. (2016). Public governance and economic growth in the transitional economies of the European Union. Transylvanian Review of Administrative Sciences, 12(48), 5-18.

Becker, G. S., Glaeser, E. L., \& Murphy, K. M. (1999). Population and economic growth. American Economic Review, 89(2), 145-149.

Benhabib, J., \& Przeworski, A. (2010). Economic growth under political accountability. International Journal of Economic Theory, 6(1), 77-95.

Bercu, A.-M., Paraschiv, G., \& Lupu, D. (2019). Investigating the energy-economic growthgovernance nexus: Evidence from central and eastern european countries. Sustainability, 11(12), 3355.

Borja, K. (2017). Corruption indicators, foreign capital, and economic growth in developing countries. The Journal of Developing Areas, 51(4), 95-107.

Boţa-Avram, C., Groşanu, A., Răchişan, P.-R., \& Gavriletea, M. D. (2018). The bidirectional causality between country-level governance, economic growth and sustainable development: A cross-country data analysis. Sustainability, 10(2), 502.

Carree, M. A., \& Thurik, A. R. (2010). The impact of entrepreneurship on economic growth. In Handbook of entrepreneurship research (pp. 557-594). Springer.

Cebula, R. J., \& Mixon Jr, F. G. (2014). The roles of economic freedom and regulatory quality in creating a favorable environment for investment in energy $\mathrm{R} \& \mathrm{D}$, infrastructure, and capacity. American Journal of Economics and Sociology, 73(2), 299-324.

Cieślik, A., \& Goczek, Ł. (2018). Control of corruption, international investment, and economic growth-Evidence from panel data. World Development, 103, 323-335.

DOĞANAY, M. A., \& DEĞER, M. (2021). INSTITUTIONS AND ECONOMIC GROWTH IN DEVELOPING COUNTRIES: DYNAMIC PANEL DATA ANALYSIS. Pamukkale Üniversitesi Sosyal Bilimler Enstitüsü Dergisi, 42, 141-154.

Fayissa, B., \& Nsiah, C. (2013). The impact of governance on economic growth in Africa. The Journal of Developing Areas, 91-108.

Feng, Y. (2003). Democracy, governance, and economic performance: Theory and evidence. MIT press.

Fukuyama, F. (2013). What is governance? Governance, 26(3), 347-368.

Greene, W. H. (2012). Econometric Analysis 7th ed (International). 
Güvercin, D., \& Adem, G. (2019). Institutions, financial development and economic growth. Dumlupinar Üniversitesi Sosyal Bilimler Dergisi, 60, 124-141.

Hausman, J. A. (1978). Specification tests in econometrics. Econometrica: Journal of the Econometric Society, 1251-1271.

Hoinaru, R., Buda, D., Borlea, S. N., Văidean, V. L., \& Achim, M. V. (2020). The Impact of Corruption and Shadow Economy on the Economic and Sustainable Development. Do They "Sand the Wheels" or "Grease the Wheels"? Sustainability, 12(2), 481.

Ibarra-Yunez, A., \& Pérez-Henríquez, B. (2017). Government Effectiveness and Regulatory Quality and Their Impact on Output Growth in Renewable Energy. Available at SSRN 2922182.

Issever Grochová, L. (2015). Regulatory quality and sustainable economic development. Acta Universitatis Agriculturae et Silviculturae Mendelianae Brunensis, 62(6), 1301-1308.

Ivanyna, M., Moumouras, A., \& Rangazas, P. (2016). The culture of corruption, tax evasion, and economic growth. Economic Inquiry, 54(1), 520-542.

Jalilian, H., Kirkpatrick, C., \& Parker, D. (2006). Creating the conditions for international business expansion: The impact of regulation on economic growth in developing countries-a cross-country analysis. Regulating Development: Evidence from Africa and Latin America, 11.

Kim, E., Ha, Y., \& Kim, S. (2017). Public debt, corruption and sustainable economic growth. Sustainability, 9(3), 433.

Levy, B. (2007). State capacity, accountability and economic development in Africa. Commonwealth \& Comparative Politics, 45(4), 499-520.

Liu, J., Tang, J., Zhou, B., \& Liang, Z. (2018). The effect of governance quality on economic growth: Based on China's provincial panel data. Economies, 6(4), 56.

Memili, E., Fang, H., Chrisman, J. J., \& De Massis, A. (2015). The impact of small-and medium-sized family firms on economic growth. Small Business Economics, 45(4), 771-785.

Mongale, I. P., \& Masipa, T. S. (2019). Human capital development, regulatory quality and economic growth Nexus: Ardl approach. Affrika, 9(1), 271-291.

Morozumi, A., \& Veiga, F. J. (2016). Public spending and growth: The role of government accountability. European Economic Review, 89, 148-171.

Nguyen, C. P., Su, T. D., \& Nguyen, T. V. H. (2018). Institutional quality and economic growth: The case of emerging economies. Theoretical Economics Letters, 8(11), 1943.

Peterson, E. W. F. (2017). The role of population in economic growth. Sage Open, 7(4), 2158244017736094.

Rivera- Batiz, F. L. (2002). Democracy, governance, and economic growth: Theory and evidence. Review of Development Economics, 6(2), 225-247.

Rothstein, B. O., \& Teorell, J. A. (2008). What is quality of government? A theory of impartial government institutions. Governance, 21(2), 165-190.

Salawu, M. B., Yusuff, A., Salman, K. K., Ogunniyi, A. I., \& Rufa, A. (2018). Does Governance Influence Economic Growth in Sub-Saharan Africa. Global Journal of Human-Social Science: E Economics, 18(1), 57-66.

Samarasinghe, T. (2018). Impact of governance on economic growth.

Sharma, C., \& Mitra, A. (2019). Corruption and economic growth: Some new empirical evidence from a global sample. Journal of International Development, 31(8), 691-719.

Sharma, S. D. (2007). Democracy, good governance, and economic development. Taiwan Journal of Democracy, 3(1), 29-62.

Stock, J. H., \& Watson, M. W. (2015). Introduction to econometrics. 
Thach, N. N., Duong, M. B., \& Oanh, T. T. K. (2017). Effects of corruption on economic growth-empirical study of Asia countries. Imperial Journal of Interdisciplinary Research, 7, 791-804.

Vijayakumar, N., Sridharan, P., \& Rao, K. C. S. (2010). Determinants of FDI in BRICS Countries: A panel analysis. International Journal of Business Science \& Applied Management (IJBSAM), 5(3), 1-13.

World Bank. (2021a). International Development, Poverty, \& Sustainability [Text/HTML]. World Bank. https://www.worldbank.org/en/home

World Bank. (2021b). The Worldwide Governance Indicators. https://info.worldbank.org/governance/wgi/

Yerrabati, S., \& Hawkes, D. (2015). Economic Governance and Economic Growth in South and East Asia \& Pacific Region: Evidence from Systematic Literature Reviews and Metaanalysis. Advances in Economics and Business, 3(1), 1-21.

Yusuf, M., Malarvizhi, C., Mazumder, M. N. H., \& Su, Z. (2014). Corruption, poverty, and economic growth relationship in the Nigerian economy. The Journal of Developing Areas, 95-107. 